\title{
Direct and Indirect Veneers to Correct Tooth Color, Form and Alignment. Cases Report:
}

\author{
Prof. Dr. Abdulkarim J. Al-Azzawi \\ B.D.S, M.Sc \\ Dr. Zainab Salman Jawad \\ B.D.S, H.D.D, M.Sc
}

\begin{abstract}
Significant improvements in tooth colored restorative materials and adhesive techniques have resulted in numerous conservative esthetic treatment possibilities. Direct composite veneers are cheaper alternative to other types of veneers such as porcelain veneers and no-prep. veneers e.g. lumineers. They are composed from combination of materials which reduces the cost and makes them an affordable alternative.

Porcelain veneers are steadily increasing in popularity among today's dental practitioners for conservative restoration of anesthetic anterior teeth ${ }^{(1)}$.
\end{abstract}

\section{CITE THIS ARTCLE}

Al-Azzawi A, Jawad Z. Direct and Indirect Veneers to Correct Tooth Color, Form and Alignment. Cases Report:. Iraqi Dent. J. 2015; 37(3):134-136. http://www.iraqidentaljournal.com

\section{INTRODUCTION}

The use of veneers in dentistry is not a new concept. In the early 1930 s the appearance of picture perfect teeth on the screen was due to Dr.Charles pincus pioneering work with porcelain laminates ${ }^{(2)}$.

Direct composite veneers became a more conservative alternative to porcelain and with the advent of microhybrid and nanohybrid composites, the finishing and polishing of these restorations can rival that of porcelain ${ }^{(3,4)}$. In 1997, Lambrechts et al found an $89 \%$ success rate in terms of esthetics of direct composite veneers to maxillary anterior teeth after five years and the esthetics and durability of these materials has improved dramatically since then however, obtaining optimal results with direct composite restorations can provide a technical challenge in certain circumstances, particularly when treating multiple teeth ${ }^{(4)}$.

Porcelain laminate veneers have been used primarily to solve esthetic problems. When diastema spaces are present they can been restored with porcelain veneers. Porcelain veneers harmonize the tooth size and to stabilize the occlusion. ${ }^{(5)}$ The indirect materials available today for use in closing diastemas include a pressable material (IPS e.max ${ }^{\circledR}$ Press Ivoclar Vivadent AG, Schaan, Liechtenstein). This system is a castable glass ceramic, composed primarily of a modified lithium disilicate glass ceramic. It demonstrates high strength, natural optical properties, and the ability to be pressed thin. Skilled ceramists can press lithium- disilicate veneers as thin as $0.3 \mathrm{~mm}$ and the material will still demonstrate a strength of $400 \mathrm{MPa}{ }^{(6-8)}$

\section{Case 1}

A 25 years old female presented dental clinic with a discolored, short protruded maxillary right central incisor and maxillary left central incisor with oblique mesial angle fracture .The two centrals indicated for direct composite veneer. Radiograph shows satisfied root canal treatment in right central incisor with metal screw and composite build up.

\section{Treatment provided}

- Direct composite veneer was the treatment of choice for both maxillary central incisors with more layers for the left one to be at the same level with the anterior arch.

- On the labial surface of the maxillary right central incisor veneer preparation was made with rounded end diamond bur to a depth of $0.5 \mathrm{~mm}$ which is enough to remove the discoloration (Figure 1).

- The gingival margin was positioned just at gingival crest. The interproximal margin was extended into the facial and gingival embrasures and located just facial to the proximal contacts. On the other hand no preparation was needed for the maxillary left incisor.

Then the teeth were etched with 35\% phosphoric acid gel (Swiss TEC) and the bonding( ExciTE from Ivoclar Vivadent) was applied to the labial surface of both centrals. One layer of nanofilled compoite (Tetric $\mathrm{N}$ ceram)] (about $0.5 \mathrm{~mm}$ ) in thickness was succeeded in masking the discoloration .

One the labial surface of left central $1 \mathrm{~mm}$ thickness of Tetric $\mathrm{N}$ ceram composite added to be with the level protruded tooth. (Figure 2-4). 


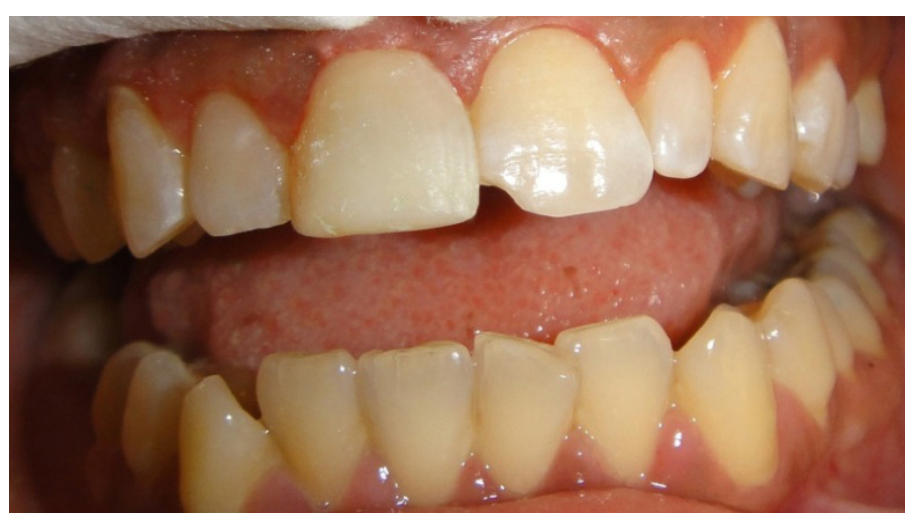

Figure 1

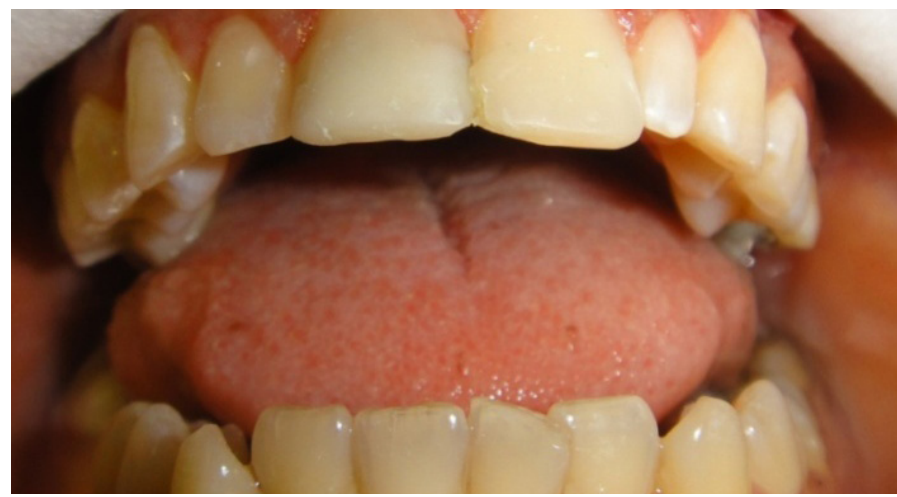

Figure 2

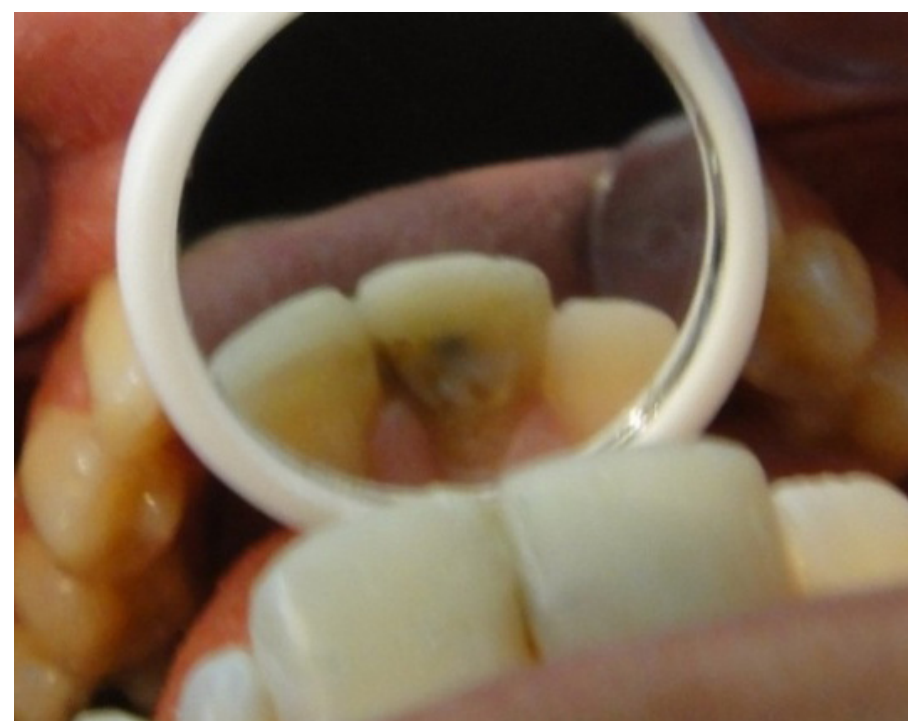

Figure 3

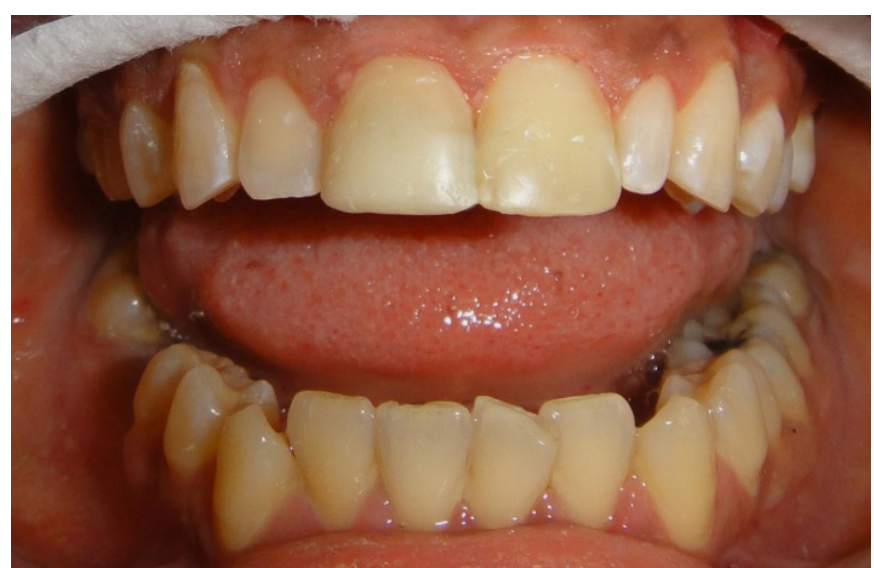

Figure 4

\section{Case 2}

A 42 year old female patient attended for esthetic treatment of a large diastema and chipping of incisal edge of maxillary central incisors. (Figure 5). The patient had no deep bite and history of parafunction and had enough surface area of enamel for bonding the restoration.

\section{Treatment plan objectives include:}

1.Reducing the diastema between maxillary central incisors.

2.Adding length and thickness to the maxillary central incisors.

All of these concerns could be addressed with porcelain veneers.

\section{Treatment provided}

Composite Mock-ups were made to find the fine balance between length, width and position of each frontal tooth. The relationship between the lips and teeth in functional movement, rest position and phonetics was tested. Based on the composite mockup, a diagnostic wax-up was made. An index in putty silicone was taken and sent to the laboratory. Prior to the start of teeth preparation, the color of ceramic veneers was chosen. The finished preparation is presented in Figure 6 and 7 . The reduction was accentuated for the incisal part of two centrals. Only slight reduction was used for facial part of teeth without opening the distal contact to allow for addition of porcelain without creating over-contoured restorations. Full arch impressions were taken with a polyvinyl siloxane impression material and an occlusal registration was made. Laboratory instructions were given to the technician.

The next step was to fabricate the provisional restorations. At the dental laboratory, refractory stone models of the prepared teeth were made and two veneers from (IPS e.max ${ }^{\circledR}$ Press system, Ivoclar Vivadent AG, Schaan, Liechtenstein) were fabricated. The two veneers were inspected in the dental office prior to the appointment of the seating. After checking in patient mouth the porcelain veneers were etched with hydrofluoric acid and at the same time the two centrals etched with $35 \%$ phosphoric acid after isolation with cotton roll and saliva ejector the veneers cemented with resin cement Relay $\mathrm{X}$ from 3M ESPE (dual cured) . (Figure 8)

Excess luting resin was removed and the margins were polished using a rubber polishing cup in a slowspeed handpiece. Excess interproximal resin was removed with a finishing strip, and the interproximal surfaces 


\section{Conservative Dentistry}

were polished with aluminum oxide coated strips. Articulating paper was used to check the occlusion, and slight adjustments were made using fine finishing diamonds.

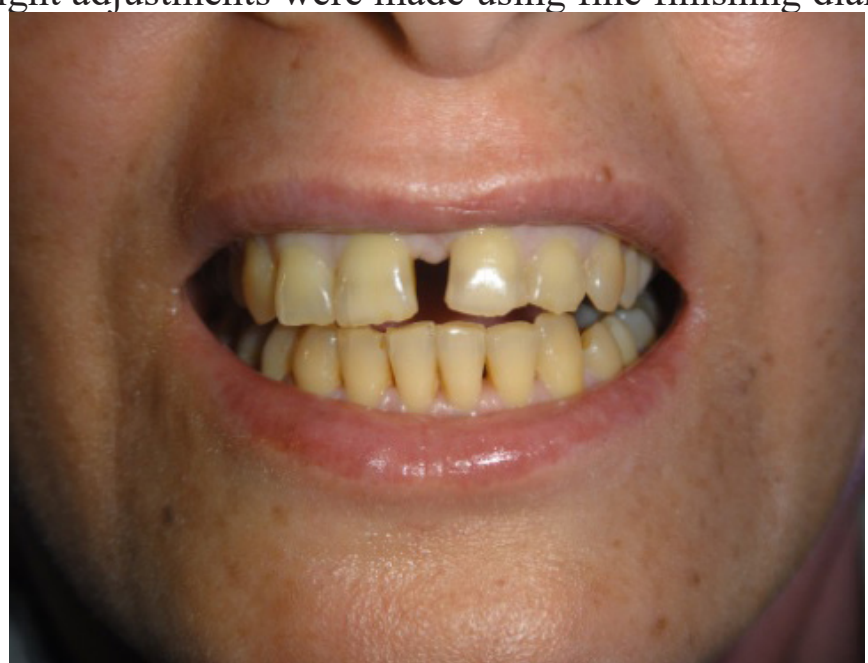

Figure 5

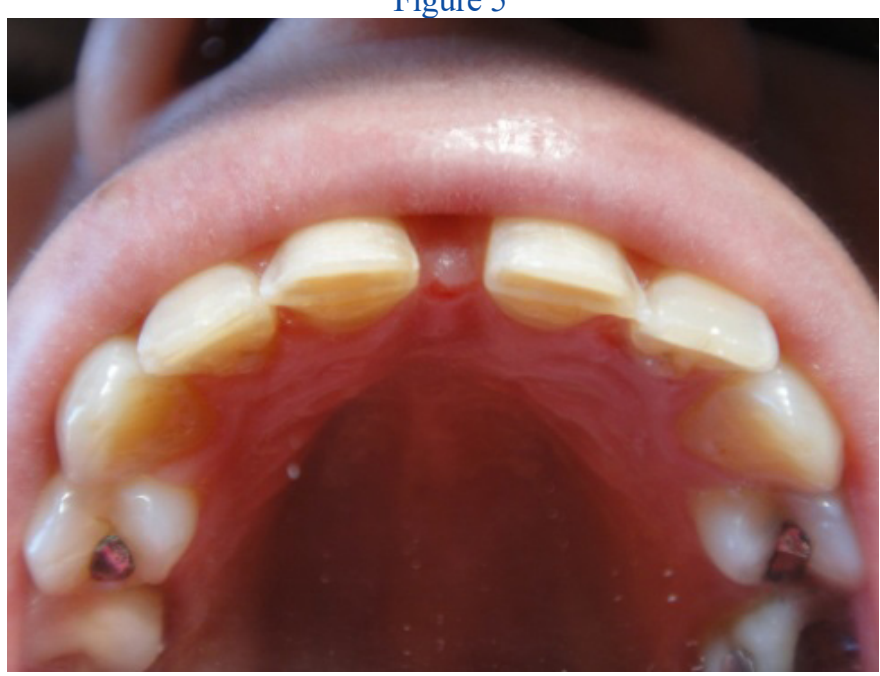

Figure 7

\section{REFERENCES}

1. Peumans M, Van Meerbeck SI, Lambrecht P, Vancherle G Porcelain veneers: a review of the literature, J Dent 2000 March; 28(3); 163-77

2. Pincus CL. Building mouth personality. California state Dental Association 1937; San Jose, California.

3. Fahl N Jr. Achieving Ultimate anterior esthetics with a new micro hybride composite. Compend Contin Educ Dent suppl 2000; (26)4-13

4. Fahl N Jr. A polychromatic composite layering approach for / solving complex class IV / direct veneer / diastema combination: part II . Pract proced aesthet dent 2007; (19) $17-22$.

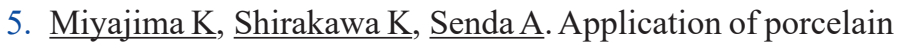

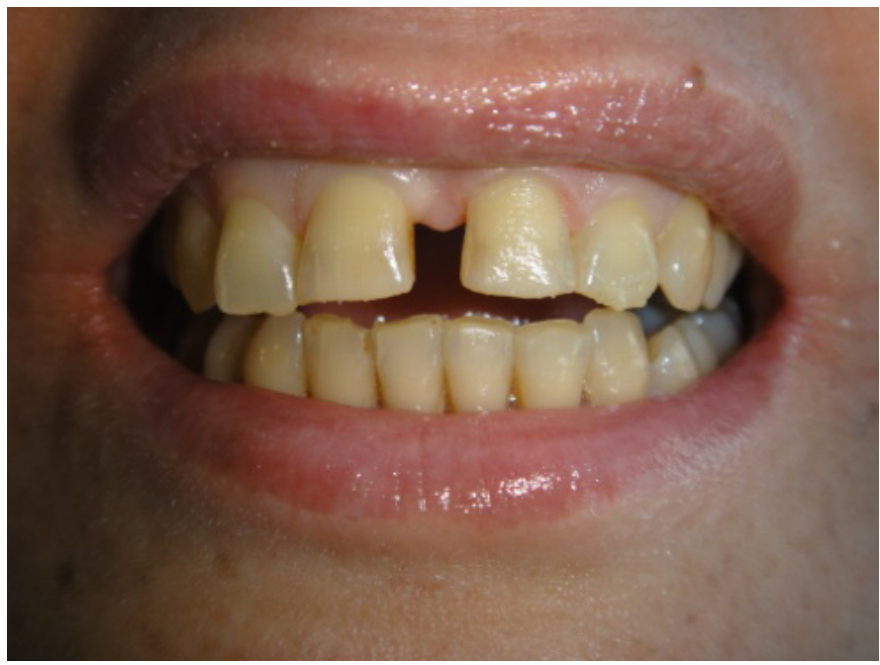

Figure 6

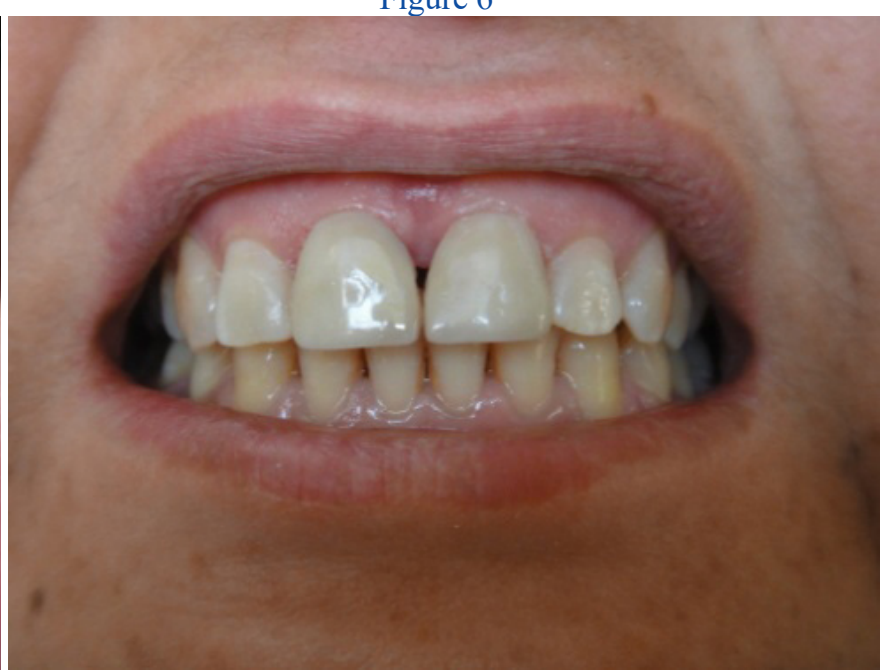

Figure 8

veneers following orthodontic treatment. $\mathrm{J}$ Can Dent Assoc 1993; Feb: 59(2):167-70.

6. Esquivel-Upshaw JF, Young H, Jones J, Yang M, Anusavice KJ. In vivo wear of enamel by a lithia disilicate-based core ceramic used for posterior fixed partial dentures: First-year results. The International Journal of Prosthodontics 2006; 19: 391-6.

7. Etman MK, Woolford MJ. Three-year clinical evaluation of two ceramic crown systems: A preliminary study. The Journal of Prosthetic Dentistry 2010; 103: 80-90.

8. Reynolds JA, Roberts M. Lithium-Disilicate Pressed Veneers for Diastema. Inside Dentistry 2010; May: insidedentistry. net 